\title{
Magnetic properties of the non-stoichiometric $\mathrm{TbCo}_{2} \mathrm{Ni}_{x}$ alloys
}

\author{
Alexander Inishev", Evgeny Gerasimov, Nikolay Mushnikov, Pavel Terentev, and Vasily Gaviko \\ M.N. Miheev Institute of Metal Physics UB RAS, Ekaterinburg, Russia \\ Institute of Natural Sciences and Mathematics, Ural Federal University, Ekaterinburg, Russia
}

\begin{abstract}
The magnetic and magnetothermal properties of the non-stoichiometric $\mathrm{TbCo}_{2} \mathrm{Ni}_{x}(0 \leq x \leq 0.2)$ alloys were studied. It was found that the concentration dependence of the Curie temperature and magnetic moment of the $3 \mathrm{~d}$-sublattice have a maximum at $x=0.025$. The obtained experimental magnetic properties of the $\mathrm{TbCo}_{2} \mathrm{Ni}_{x}$ alloys were discussed under assumption that the Co magnetic moment in the compounds changes with increasing $x$. The magnetic entropy change was determined using the temperature dependences of the magnetization and Maxwell's thermodynamic relation. The obtained results for $\mathrm{TbCo}_{2} \mathrm{Ni}_{x}$ were compared with those for the $\mathrm{ErCo}_{2} \mathrm{Mn}_{x}$ alloys.
\end{abstract}

\section{Introduction}

It was found recently that ternary $R M_{2} \mathrm{Mn}(R$ - rare-earth metal, $M-3 \mathrm{~d}$ transition metal $\mathrm{Ni}, \mathrm{Co}$ ) compounds crystallize in the Laves-phase $\mathrm{MgCu}_{2}$-type cubic structure in spite of the ratio of the $R$ and $M$ components is 1 to 3. The $\mathrm{Mn}$ atoms in Laves-phase structure of the $R M_{2} \mathrm{Mn}$ compounds partially occupy both the $M(16 \mathrm{~d})$ and rare earth (8a) sites [1-3]. The Curie temperatures $T_{\mathrm{C}}$ are considerably higher for the $R \mathrm{Ni}_{2} \mathrm{Mn}$ alloys in comparison with $T_{\mathrm{C}}$ for corresponding binary $R \mathrm{Ni}_{2}$ and $R \mathrm{Mn}_{2}$. Later, the structure and magnetic properties of the non-stoichiometric $R M_{2} \mathrm{Mn}_{x} \quad(0 \leq x \leq 1.5) \quad$ compounds with $R=\mathrm{Tb}$, Dy, Gd were studied [4-7]. It was shown that the $\mathrm{MgCu}_{2}$-type structure exists up to the manganese content $x=0.8$ for $\mathrm{ErCo}_{2} \mathrm{Mn}_{x}$ and up to $x=1.5$ for $\mathrm{ErNi}_{2} \mathrm{Mn}_{x}$. It was established that $T_{\mathrm{C}}$ is a nonmonotonous function of $\mathrm{Mn}$ concentration, which has a maximum at $x<1$. It was found also that the maximum isothermal entropy change and the adiabatic temperature change remain weakly changed in a wide temperature range in $\mathrm{ErCo}_{2} \mathrm{Mn}_{x}$. Thus, there is new opportunity to modify magnetic properties of the Laves phase compounds by adding $\mathrm{Mn}$ and forming nonstoichiometric $R M_{2} \mathrm{Mn}_{x}$ compounds.

Up to now the properties of $R M_{2} M_{x}^{\prime}$ - type compounds with $M^{`}=\mathrm{Mn}$ were studied only. However, we expect that non-stoichiometric $R M_{2} M_{x}$ compounds with another $3 \mathrm{~d}$ transition metals can exist. In particularly, such type compounds can forms in case $M=\mathrm{Ni}$.

In the present paper, we report the results of studies of the structure, magnetic and magnetothermal properties of the non-stoichiometric $\mathrm{TbCo}_{2} \mathrm{Ni}_{x}$. The obtained results are compared with those for $\mathrm{ErCo}_{2} \mathrm{Mn}_{x}$ which we previously studied.

\section{Experimental details}

The ingots of the $\mathrm{TbCo}_{2} \mathrm{Ni}_{x}$ alloys were prepared by induction melting of the constituents in alumina crucibles in argon atmosphere. In order to obtain the equilibrium phase state, the ingots were annealed at $800^{\circ} \mathrm{C}$ for 7 days. Structural and magnetic studies were performed at the Centre of Collective Use of the Institute of Metal Physics UB RAS. Room temperature X-ray diffraction patterns were measured for powdered samples with the average particle size $30-50 \mu \mathrm{m}$ using a DRON-type diffractometer with $\mathrm{Cr} \mathrm{K} \alpha$ radiation. The $\mathrm{x}-$ ray diffraction patterns were analysed with the PowderCell 2.4 program. To determine the Curie temperature of the compounds, we measured temperature dependences of ac magnetic susceptibility $\chi_{\mathrm{ac}}$ and used the position of minimum in the temperature dependences of derivative $\mathrm{d} \chi_{\mathrm{ac}}(\mathrm{T}) / \mathrm{dT}$, which corresponds to the more abrupt decrease in the susceptibility with increasing temperature. The spontaneous magnetization $\mu_{\mathrm{s}}$ of compounds was determined from the demagnetization curves as magnetization extrapolated to zero internal field.

\section{Results and discussion}

Fig. 1 shows the room temperature X-ray diffraction patterns of $\mathrm{TbCo}_{2} \mathrm{Ni}_{x}$ alloys. All main reflections in the $\mathrm{X}$-ray diffraction patterns are adequately described in terms of the $\mathrm{MgCu}_{2}$-type structure $(F d 3 m)$; the volume fraction of impurity phases with the $\mathrm{PuNi}_{3}$-type structure $(R 3 m)$ does not exceed 8 vol. \%. According to X-ray diffraction studies, the single phase non-stoichiometric $\mathrm{TbCo}_{2} \mathrm{Ni}_{x}$ compounds with the cubic Laves-phase structure exist up to critical nickel concentration $x=0.1$ [8]. This value is much lower than $x=0.8-1.5$ which 


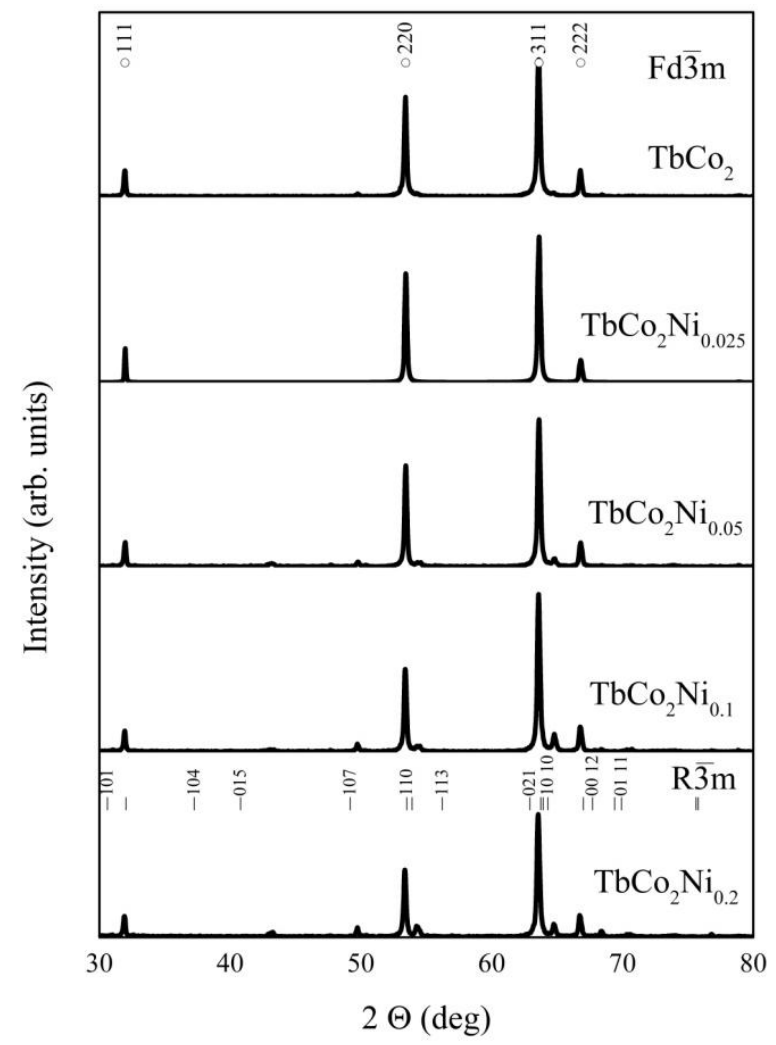

Fig. 1. X-ray diffraction patterns of $\mathrm{TbCo}_{2} \mathrm{Ni}_{x}$ alloys with different $x$. Bragg peak positions are indicated by the markers for $\mathrm{MgCu}_{2}$-type structure (open circles). $\mathrm{PuNi}_{3}$-type structures (line bars).

were observed early for non-stoichiometric $R M_{2} \mathrm{Mn}_{x}$ compounds. It is known that the stability of the Laves phases is determined by factors such as the relationship of atomic radii of $\mathrm{R}$ and $\mathrm{M}$ elements and the average number of valence electrons per atom. The chemical bonds in Laves phases are assumed to be mixed metallic-covalence-ionic. Because of this, to analyse the stability of the phases, atomic radii of elements are sometimes used. It is likely that the same factors must affect the concentration boundaries of the existence of the nonstoichiometric compounds. This may be due to that the atomic and ionic radii of $\mathrm{Ni}$ are less than those of $\mathrm{Mn}$. And, correspondingly, large difference between $\mathrm{Ni}$ and $R$ does not allows to occupy enough amount of $R$ (8a) sites by $\mathrm{Ni}$ atoms. Thus, the non-stoichiometric $R \mathrm{Co}_{2} \mathrm{Ni}_{x}$ alloys with cubic $\mathrm{MgCu}_{2}$-type Laves phase structure can be obtained in more narrow concentration range than in case of alloying with $\mathrm{Mn}$.

The lattice parameter of the Ni-containing compounds are virtually independent of $x$ (Fig. 2). Such behavior caused by two opposite factors. It is known that the atoms of the alloying element ( $\mathrm{Ni}$ or $\mathrm{Mn}$ ) occupy both the $R(8 \mathrm{a})$ and the $M(16 \mathrm{~d})$ sites. The partial substitution of the $R$ atoms by $\mathrm{Ni}$ or $\mathrm{Mn}$ at the $8 \mathrm{a}$ sites leads to decrease the lattice parameter. On the other hand, the substitution of the Co atoms at the $16 \mathrm{~d}$ sites by a $3 \mathrm{~d}$ element with a larger ionic or metallic radius leads to increasing of the lattice parameter. Two opposite tendencies lead to a weak concentration change of the lattice parameter for $R M_{2} M_{x}$.

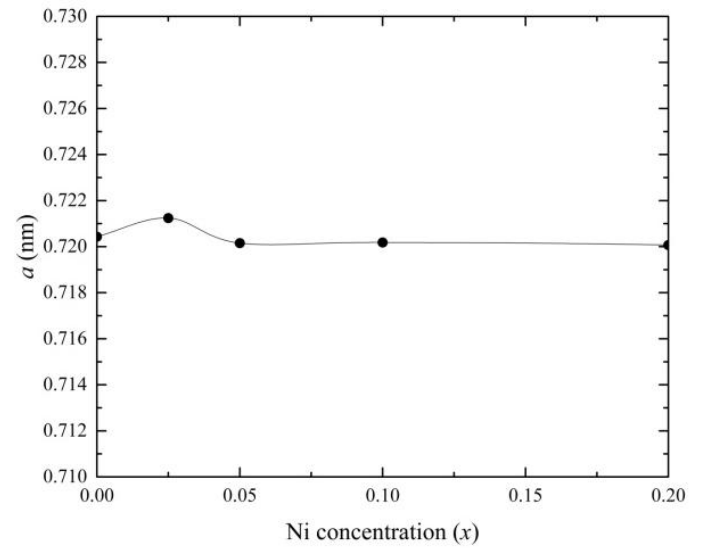

Fig. 2. Concentration dependences of the lattice parameter for $\mathrm{TbCo}_{2} \mathrm{Ni}_{x}$ compounds.

Fig. 3 shows the concentration dependences of the Curie temperature for $\mathrm{ErCo}_{2} \mathrm{Mn}_{x}$ and $\mathrm{TbCo}_{2} \mathrm{Ni}_{x}$ compounds in range of concentration from $x=0$ up to maximal concentration for which exist single phase nonstoichiometric $\mathrm{TbCo}_{2} \mathrm{Ni}_{x}$ compounds with $\mathrm{MgCu}_{2}$-type structure.

As can be seen in Fig. 3, concentration dependence of the Curie temperature increases sharply at small $\mathrm{Ni}$ concentrations and has maximum at $T=233 \mathrm{~K}$. With further increasing the $\mathrm{Ni}$ content, the concentration dependence of the $T_{\mathrm{C}}$ decreases. The Curie temperature of $\mathrm{ErCo}_{2} \mathrm{Mn}_{x}$ compounds monotonically increases and reaches maximum value $212 \mathrm{~K}$ at manganese concentration $x=0.6[6]$.

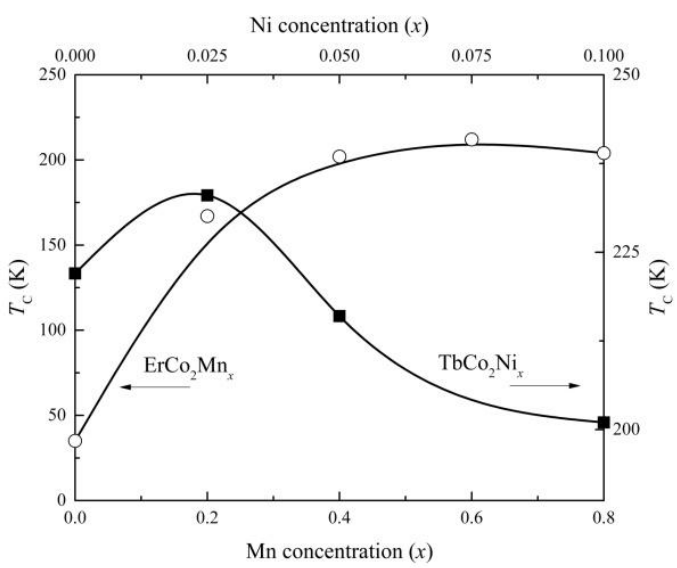

Fig. 3. Concentration dependences of the Curie temperature for $\mathrm{ErCo}_{2} \mathrm{Mn}_{x}(\circ)$ and $\mathrm{TbCo}_{2} \mathrm{Ni}_{x}(\mathbf{\bullet})$ compounds.

The spontaneous magnetic moments $\mu_{\mathrm{s}}$ decreases with increasing $x$ both for $\mathrm{TbCo}_{2} \mathrm{Ni}_{x}$ and for $\mathrm{ErCo}_{2} \mathrm{Mn}_{x}$ as result of antiparallel ordering of magnetic moments of heavy rare-earth ions and 3d-transition atoms (Fig. 4).

Fig. 5 shows the concentration dependence of the magnetic moment of $3 \mathrm{~d}$-sublattice of $\mathrm{ErCo}_{2} \mathrm{Mn}_{x}$ and $\mathrm{TbCo}_{2} \mathrm{Ni}_{x}$ compounds. We calculated magnetic moment of $3 \mathrm{~d}$-sublattice $\mu_{3 \mathrm{~d}}$ in assumption that the $R$ and $3 \mathrm{~d}$ magnetic moments have collinear antiparallel alignment: 


$$
\mu_{3 \mathrm{~d}}=\left(\mu_{R}-\mu_{\mathrm{s}}\right) /(2+x),
$$

where $\mu_{\mathrm{s}}$ - spontaneous magnetic moment of the compounds, $\mu_{R}$ - magnetic moment of the rare-earth ion. The maximum $\mu_{3 \mathrm{~d}}$ value is $1.38 \mu_{\mathrm{B}}$ for $\mathrm{TbCo}_{2} \mathrm{Ni}_{0.025}$ compound and $1.5 \mu_{\mathrm{B}}$ for $\mathrm{ErCo}_{2} \mathrm{Mn}_{0.6}$ compound. It is seen that character of the $\mu_{3 \mathrm{~d}}(x)$ concentration dependencies both for $\mathrm{ErCo}_{2} \mathrm{Mn}_{x}$ and for $\mathrm{TbCo}_{2} \mathrm{Ni}_{x}$ is very similar to those for Curie temperatures.

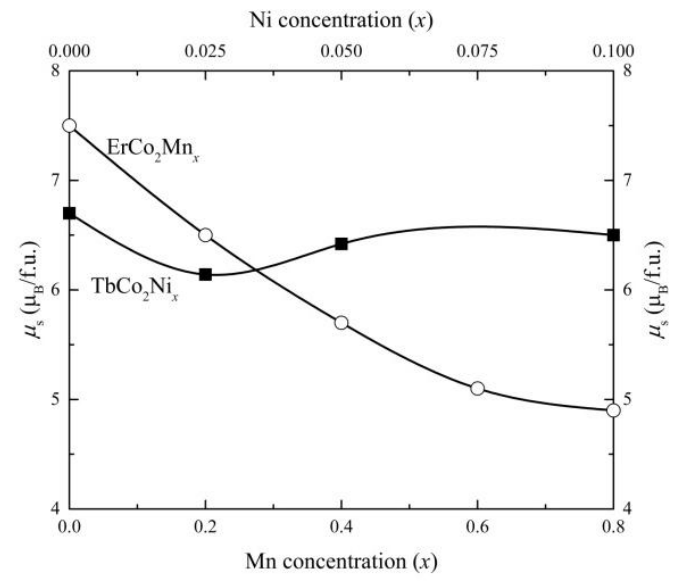

Fig. 4. Concentration dependences of the spontaneous magnetic moment at $4 \mathrm{~K}$ for $\mathrm{ErCo}_{2} \mathrm{Mn}_{x}(\mathrm{O})$ and $\mathrm{TbCo}_{2} \mathrm{Ni}_{x}(\mathbf{m})$ compounds.

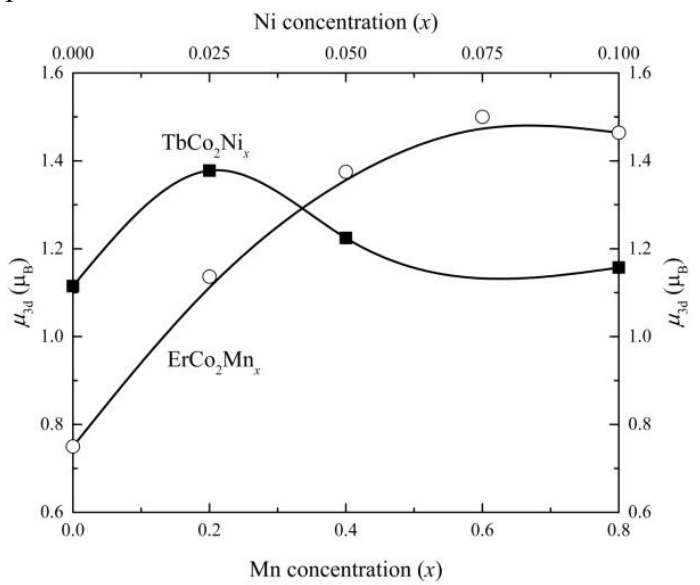

Fig. 5. Concentration dependences of the magnetic moment of $3 d$-sublattice for $\mathrm{ErCo}_{2} \mathrm{Mn}_{x}(\mathrm{O})$ and $\mathrm{TbCo}_{2} \mathrm{Ni}_{x}(\mathbf{m})$ compounds.

The $\mu_{3 \mathrm{~d}}(x)$ dependence has maximum for $\mathrm{TbCo}_{2} \mathrm{Ni}_{x}$ and is monotonous for $\mathrm{ErCo}_{2} \mathrm{Mn}_{x}$. Our analysis of magnetic moments shows that the increase in the Curie temperature of the compounds is mainly due to changes in the band structure. It is possible, that alloying with Mn and $\mathrm{Ni}$ increase the Co magnetic moment due to the additional splitting of the $3 \mathrm{~d}$ band. This, in turn, leads to an increase in the $R$-Ni $(\mathrm{Mn})$, Co-Ni $(\mathrm{Mn})$ exchange interaction.

We measured temperature dependences of magnetization $M(T)$ in magnetic field $H_{l}=1 \mathrm{~T}$. It allows us to determine temperature variation of the magnetic entropy change $\Delta S_{\mathrm{m}}(T)$ in $\mathrm{TbCo}_{2} \mathrm{Ni}_{x}$ compounds for magnetic field change $\mu_{0} \Delta H=H_{1}-0=1 \mathrm{~T}$ using well known Maxwell`s thermodynamic relation:

$$
\Delta S_{\mathrm{m}} T, \Delta H={ }_{0}^{H_{1}}\left(\frac{\partial M T, H}{\partial T}\right)_{H} \mathrm{~d} H \approx \frac{\partial M T, H_{1}}{\partial T} H_{1} .
$$

Fig. 6 shows the temperature dependences of entropy change for $\mathrm{ErCo}_{2} \mathrm{Mn}_{x}$ and $\mathrm{TbCo}_{2} \mathrm{Ni}_{x}$ compounds. Maximum isothermal entropy change is $-1.1 \mathrm{~J} \mathrm{~kg}^{-1} \mathrm{~K}^{-1}$ for $\mathrm{TbCo}_{2} \mathrm{Ni}_{0.025}$ and $-1.15 \mathrm{~J} \mathrm{~kg}^{-1} \mathrm{~K}^{-1}$ for $\mathrm{ErCo}_{2} \mathrm{Mn}_{0.2}$ for the magnetic field change $1 \mathrm{~T}$. These values are close to those observed, for the binary $\mathrm{TbCo}_{2}$-based compounds.

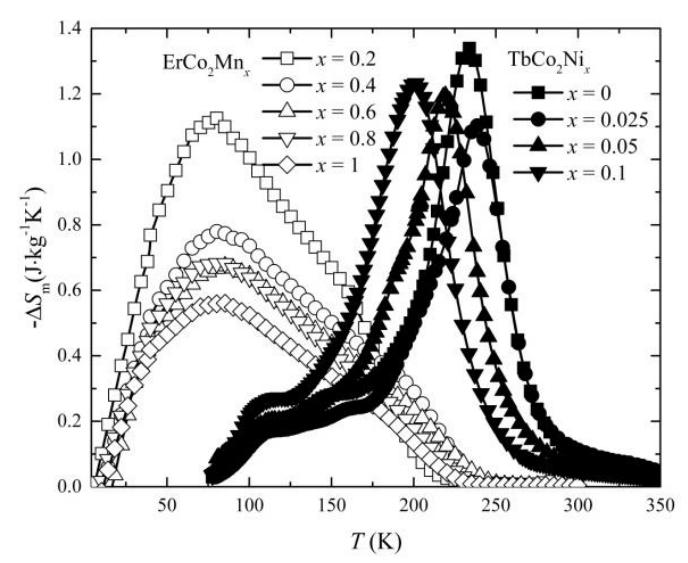

Fig. 6. Temperature dependences of entropy change of $\mathrm{ErCo}_{2} \mathrm{Mn}_{x}$ and $\mathrm{TbCo}_{2} \mathrm{Ni}_{x}$ compounds for magnetic field change $\mu_{0} \Delta H=1 \mathrm{~T}$.

The magnitudes of $\Delta S_{\mathrm{m}}(T)$ decrease with increasing $M$ concentration because of decreasing the spontaneous magnetic moment of compounds. The behaviour of the $\Delta S_{\mathrm{m}}(T)$ curves strongly differs. For $\mathrm{TbCo}_{2} \mathrm{Ni}_{x}, \Delta S_{\mathrm{m}}(T)$ curves have maximum near $T_{\mathrm{C}}$ whereas, for $\mathrm{ErCo}_{2} \mathrm{Mn}_{x}$ maxima are observed at temperatures which are much lower than $T_{\mathrm{C}}$. Such difference arises because $\Delta S_{\mathrm{m}}(T)$ shape depends on shape of temperature dependence of resultant magnetization which reflects a non-Brillouin behavior of the resultant magnetization of the ferrimagnetically ordered $R$ and $M\left(M^{\prime}\right)$ magnetic sublattices.

\section{Conclusion}

We studied the effect of $\mathrm{Ni}$ alloying on the structure, magnetic and magnetothermal properties of $\mathrm{TbCo}_{2} \mathrm{Ni}_{x}$ alloys. It was established that single-phase nonstoichiometric compounds with the cubic $\mathrm{MgCu}_{2}$-type structure are formed at the Ni content $x \leq 0.1$.

We found that concentration dependences of the Curie temperature and magnetic moment of $3 \mathrm{~d}$-sublattice have maximum at $\mathrm{Ni}$ content $x=0.025$. Our analysis shows that all these changes are associated with changes in the Co magnetic moment which can arise from changes of compounds electron band structure.

Using magnetization measurements, we estimated the magnetocaloric effect in the $\mathrm{ErCo}_{2} \mathrm{Mn}_{x}$ and $\mathrm{TbCo}_{2} \mathrm{Ni}_{x}$ compounds. The maximum values of the $\Delta S_{\mathrm{m}}$ of $\mathrm{TbCo}_{2} \mathrm{Ni}_{x}$ compounds are sufficiently close for all nickel concentrations.

The research was carried out within the state assignment of FASO of Russia (theme "Magnet" No. AAAA-A18118020290129-5) and supported by project of UB RAS (No. 18-10-2-5). 


\section{References}

1. J.L. Wang, C. Marquina, M.R. Ibarra, G.H. Wu, Phys. Rev. B 73, 094436 (2006)

2. M. Bibekananda, K.G. Suresh, A.K. Nigam, J. Magn. Magn. Mater. 322, 2415 - 2418 (2010)

3. J.L. Wang, S.J. Campbell, M. Hofmann, M. Hoelzel, R. Zeng, S.X. Dou, S.J. Kennedy, J. Appl. Phys. 111, 07E334 (2012)

4. N.V. Mushnikov, V.S. Gaviko, E.G. Gerasimov, P.B. Terent'ev, I.A. Tkach, Phys. Met. Metallogr.110, 210 - 217 (2010)

5. E.G. Gerasimov, N.V. Mushnikov, P.B. Terentev, V.S. Gaviko, A.A. Inishev, J. Alloys and Compd. 571, 132 - 137 (2013)

6. E.G. Gerasimov, N.V. Mushnikov, A.A. Inishev, P.B. Terentev, V.S. Gaviko, J. Alloys and Compd. 680, $359-365$ (2016)

7. A. Aryal, A. Quetz, S. Pandey, T. Samanta, I. Dubenko, D. Mazumdar, S. Stadler, N. Ali, J. Appl. Phys. 119, 043905 (2016)

8. A.A. Inishev, E.G. Gerasimov, N.V. Mushnikov, P.B. Terentev, V.S. Gaviko, Phys. Met. Metallogr. 118, 1059 (2017) 